\title{
Experimental Study of R134a, R406A and R600a Blends as Alternative To Freon 12
}

\author{
Akintunde, M.A. \\ Mechanical Engineering Department, The Federal University of Technology,P.M.B 704, Akure, Nigeria
}

\begin{abstract}
In the vent of chlorofluorocarbons (CFCs) phase-out, identify long term alternative to meet requirements in respect of system performance and service is an important area of research in the refrigeration and are conditioning industry. This work focuses on experimental study of the performance of eco-friendly refrigerant mixtures. Mixtures of three existing refrigerants namely: R600a (n-butane), R134a (1,1, 1,2,tetrafluoroethane) and R406A (55\%R22/4\%R600a/41\%R142b)were considered for this research. These refrigerants were mixed in various ratios, studied and compared with $R-12$ (dichlorodifluoromethane) which was used as the control for the experimentation. The rig used in the experimentation is a $2 \mathrm{hp}(1.492 \mathrm{~kW})$ domestic refrigerator, designed based on $40^{\circ} \mathrm{C}$ condensing and $-10^{\circ} \mathrm{C}$ evaporating temperatures. The rig was tested with $R-12$, and blends of the three refrigerants. During the experimentation, both evaporator $\left(T_{\theta}\right)$ and condenser $\left(T_{0}\right)$ temperatures were measured. These were used to determine the heat absorbed in evaporator $\left(Q_{e}\right)$ and the heat rejected incondenser $\left(Q_{c}\right)$. The results show that $R 134 a / R 600$ a mixture in the ratio 50:50 can be used as alternative to $R-12$ in domestic refrigerators, without the necessity of changing the compressor lubricating oil. At $T_{\theta}$ of $-5^{\circ} \mathrm{C}$ and $T_{c}$ of $40^{\circ} \mathrm{C}, R-12$ gives a COP of 2.08 while $50: 50$ blend of R134a/R600a gives a COP of 2.30 under the same operating conditions.
\end{abstract}

Keywords: Refrigerants, Alternatives, Blends, COP, Performance, Comparison, new-refrigerants.

\section{Introduction}

Chlorofluorocarbons (CFCs) proved to be one of the most useful classes of compounds, ever developed as refrigeration and air conditioning working fluids called refrigerants, because of their desirable thermal properties. These refrigerants promote workers and consumers safeties because they are non-flammable, noncorrosive and very low in toxicity. As a result, these compounds are used in a wide variety of applications, such as refrigerators, foam bowings, aerosol propellants and cleaning solvents due to their desirable physical and chemical properties that enhance energy efficiency and product reliability, (Lee et al., 2002).

However, some of the properties that make CFCs desirable, such as chemical stability, had led to global environmental problems. As a result of chemical stability, CFCs have long environmental residence time and its emissions lead to accumulation in the lower atmosphere. CFCs migrate and mix with chemicals in the upper atmosphere where they dissociate, releasing chlorine atoms that catalyze the destruction of Ozone molecules. Past and recent scientific findings have clearly linked chloride from CFCs and other man-made compounds to the seasonal ozone losses over the northern and southern hemisphere, Eckels and Tesene (2003). Since ozone provides a screen against solar ultraviolet radiation (UV-B) and excess UV-B has a potential of contributing to health and environmental hazard, hence significant depletion of ozone layer should be avoided. This provides a sound basis for the Montreal Protocol, an international agreement amended in 1990 requiring a total phase out of CFCs production and consumption by 2000, (Calm, 2002).

In developing nations, the vapour compression based refrigeration; air conditioning and heat pump, continue to run on halogenated refrigerants due to its excellent thermodynamics and thermophysical properties, apart from the low cost. Hence, the need for alternative refrigerants to fulfill the objectives of the international protocol (Montreal and Kyoto) so as to satisfy the growing worldwide demand.

Refrigerant-12 (dichlorodifluoromethane), which is a chlorofluorocarbon (CFC) compound, is found to be stable in the troposphere, (Chivian et al., (1993)). It moves to the stratosphere and breaks down by strong ultraviolet light where it releases chlorine atom which then deplete the ozone layer by catalyzing the breakdown of ozone molecules. The CFCs in the stratosphere undergoes photo decomposition by the action of high energy ultraviolet radiation resulting in equation (1.1)

$$
{ }^{*} \mathrm{Cl}_{2} \mathrm{~F}_{2(\mathrm{~g})}+\mathrm{UV} \longrightarrow \mathrm{Cl}^{*}{ }_{(\mathrm{g})}+{ }^{*} \mathrm{Cl}_{2} \mathrm{~F}_{2(\mathrm{~g})}
$$

which releases chlorine atoms, denoted simply as $\mathrm{Cl}^{*}$. These atoms react with ozone, reducing it and undergo a chemical reaction as shown in equation (1.2).

$$
\mathrm{Cl}^{*}{ }_{(\mathrm{g})}+\mathrm{O}_{\mathrm{a( \textrm {g } )}} \longrightarrow{ }^{*} \mathrm{CIO}_{(\mathrm{g})}+\mathrm{O}_{2(\mathrm{~g})}
$$


In the atmosphere is an appreciable concentration of atomic oxygen by virtue of the reaction shown in equation (1.3)

$$
\mathrm{O}_{\mathrm{a}(\mathrm{g})}+\mathrm{UV} \longrightarrow \mathrm{O}_{2(\mathrm{~g})}+\mathrm{O}_{(\mathrm{g})}
$$

In the presence of Nitric oxide (NO), the "CIO species may react with either "O" or "NO", regenerating "CI" atoms and resulting in chain reaction that cause the net depletion of ozone as shown in equations.

Chlorofluorocarbons (CFCs) and hydrochlorofluorocarbon (HCFCs) have a long and successful association with the refrigeration industry. This started to decline only after the environmental hazard associated with their release into the atmosphere. The first known artificial refrigeration was by putting ethylethene to boil in a partial vacuum vessel. Methyl chloride $\left(\mathrm{CH}_{2} \mathrm{Cl}\right)$ was first employed in 1878 , and remains in use for many years until 1960s. A mixture called chemogene (consisting of petrol, ether and naphtha) was patented as a refrigerant for vapour compression system in 1866 while dimethyl-ether was introduced as a refrigerant two years later. In the same year an ice production machine that uses carbon (IV) oxide was invented, (Hwang et al., 1998).

The progression of refrigerants from early stage to the present addressing future direction and candidates, breaks the history into four refrigerant generations based on selection criteria. The generation of refrigerants are as summarized in Fig. 1 by, Calm and Didon (1997).

Alternative refrigerants are the present and future refrigerants options. Although production and use of the fully halogenated refrigerants such as R11, R12, R13,R113, R114, and R115 will be phased out under the auspice of the Montreal Protocol. The partially halogenated CFC refrigerants such as R22 and R123 may remain in use for years to come as they are not as stable fully halogenated refrigerants and cause little damages to the ozone layer, (Bhatti, 1999).

The range of possibilities includeshydrofluorocarbons (HCFCs), refrigerant mixtures and natural fluids such as shown in Table 1. Among these groups of alternatives, hydrochlorofluorocarbons(HCFCs) and the hydrofluorocarbons (HFCs) are most useful. The HCFCs were developed to serve as interim replacement for CFCs. They are used in existing equipment. HCF refrigerants are developed to serve as alternative to CFC and HCFC refrigerants, since they do not contain chlorine and have almost zero ODP. Hence, to develop possible alternative refrigerant that has zero ozone depletion potential (ODP) and, lower global warming potential (GWP), it is necessary to consider HCFs.

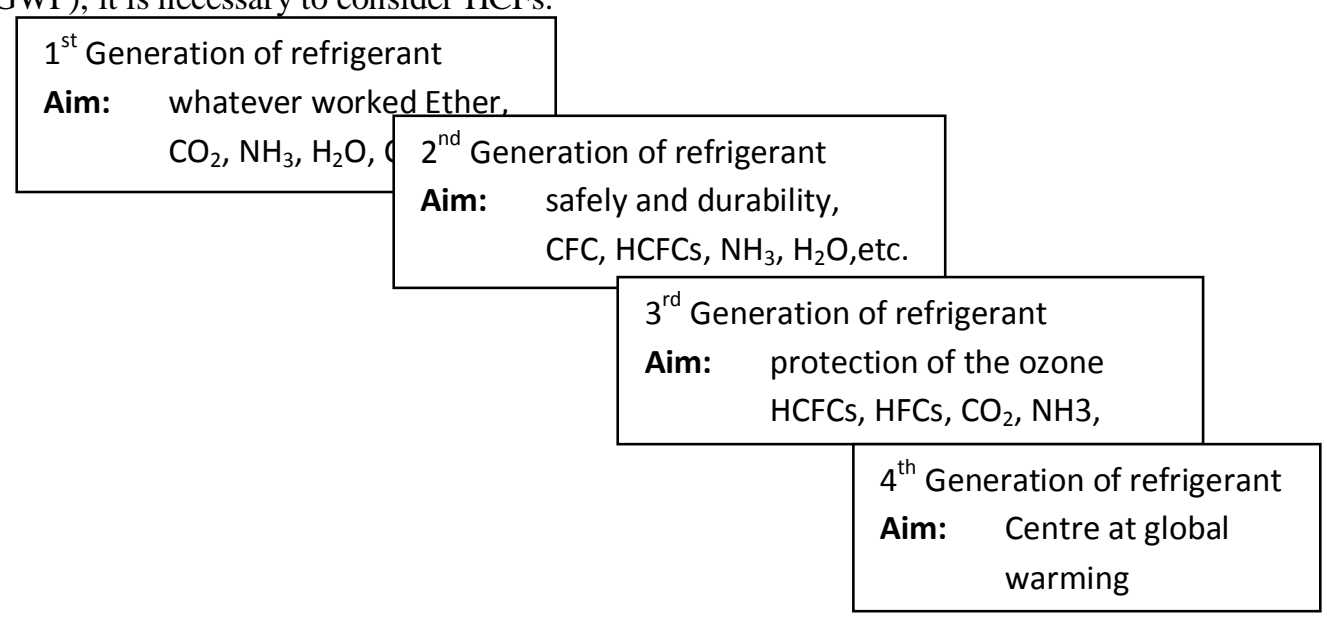

Fig. 1: The Generation of Refrigerants

In the process of searching for new alternative, since no single component refrigerant matches, hence refrigerant blends as alternative was recommended, because by mixing two or more refrigerants a new working fluid with the desired characteristic can be developed. Problem with blend of refrigerantsis that not all of the properties can match the original refrigerant under all conditions. R12 for example will rarely match the pressure at all point in the desired temperature range. What is more common is that the blend will match in one region and the pressure differs elsewhere. The mixture of refrigerants could be Azeotropic, in which two or more refrigerants with similar boiling point acts as a single fluid. The components of the mixture will not separate under normal operating conditions and can be charged as a vapour or liquid. An example of these blends is 50/50, which is the mixture of R32 and R134a. The near Azeotrope mixture consist of two or more refrigerants with different boiling points, when in liquid or vapour state, act as one component. When changing from vapour to liquid or liquid to vapour, the individual refrigerant evaporates or condenses at different temperatures. The mixture has a temperature glide of less than $10^{\circ} \mathrm{F}$ and should be charged in the liquid state to 
assume proper mixture, and the Zoetrope which is a mixture made up of two or more refrigerants with different boiling points, they are charged in the liquid state.

Table 1: List of Alternatives to CFC and HCFC Refrigerants and Their Environmental Effects

\begin{tabular}{|l|c|c|c|}
\hline Refrigerants & Boiling Point $\left({ }^{\circ} \mathrm{C}\right)$ & $\begin{array}{l}\text { Ozone } \begin{array}{c}\text { Depletion } \\
\text { Potential (ODP) }\end{array} \\
\text { Alternatives for R-12 }\end{array}$ & $\begin{array}{l}\text { Global Warming } \\
\text { Potential (GWP) }\end{array}$ \\
\hline R-12 & -29.79 & 1.0 & 8100 \\
\hline R-134a & -26.1 & 0 & 1300 \\
\hline R-410A & -33.0 & 0.037 & 1100 \\
\hline R-409A & 34.3 & 0.048 & 1400 \\
\hline \multicolumn{2}{|c|}{ Other Alternatives for R-12 } & 0.055 & 1700 \\
\hline R-22 & -40.75 & 0 & 1600 \\
\hline R-407C & -44.0 & 0 & 0 \\
\hline R-410A & -52.7 & & 0 \\
\hline \multicolumn{2}{|c|}{ Other option - natural refrigerants } & 0 & 0 \\
\hline Air & -320 & 0 & 0 \\
\hline Water & 100 & 0 & 0 \\
\hline Ammonia & -33 & 0 & 0 \\
\hline Carbon dioxide & -78 & 0 & \\
\hline
\end{tabular}

Zoetrope are similar to near azeotrope with the exception of having temperatures glide greater than $10^{\circ} \mathrm{F}$. By blending refrigerants, it is possible to create new blend that are non-flammable but still contain moderate flammable refrigerants, hence blends are created to improve such systems characteristic as compressor discharge temperature or to improve lubricant circulation by adding more lubricant mixable refrigerant. The vapour pressure of the final fluid can be tailored to match that of the CFCs or HCFCs being replaced, (Domanski and Mclinden, 1992). Lorenz and Nuetznerstudied two-evaporators of domestic refrigerator/freezer and reported power saving as high as 20 percent with a refrigerant mixture in comparison to the existing refrigerant, (Stoecker, 1983).

A single chlorine-free, replacement for R12 has been found in R134a. Some studies have been carried out on the performance of R134a compared with that of R12 in vapour compression refrigeration systems, (Akintunde, (2004); Akintunde, (2006)). Despite its better heat transfer than R12, R134a has its disadvantage as compared to R12. It has been noted that R134a is a highly fluorinated compound with higher specific volume. It absorbs more moisture than R12 at all temperatures, (Calm, et al., 2002). Therefore, the system will be more prone to rusting and copper platting due to large moisture content. Also while the ozone depletion potential (ODP) is zero the global warming potential (GWP) is very high (GWP, 1300). For these reasons, the production and use of R134a will be terminated in the near future.

Moreover, international concerns over relatively high global warming potential of R134a have made some developed nations to have a rethink about R134a as R12 replacement in the near future, (Radermecher and Kim, 2006). Therefore, other replacement will be needed that are thermodynamically attractive as R12. Other known alternative refrigerants to R12 are R152a, R410A and R407C. Eckels and Tesene (2003) compared the thermodynamic properties of R22, R134a, R410A and 407C in a range of typical condenser tubes. The average heat transfer coefficient was measured at a saturation temperature of $40^{\circ} \mathrm{C}$ over a mass flux range of 125 $\mathrm{kg} / \mathrm{m}^{2}$ sto $600 \mathrm{~kg} / \mathrm{m}^{2} \mathrm{~s}$. Local heat transfer coefficient was measured in the outer diameter of smooth and fin enhanced tubes. It was discovered that,R22 and R410A have similar performance that was slightly less than $\mathrm{R} 134 \mathrm{a}$ in $\mathrm{COP}$ and $\mathrm{R} 407 \mathrm{C}$ had the lowest performance of all the refrigerants tested. R134a has similar thermodynamic properties as R12 and has attracted the most attention as a substitute refrigerant for R12. The major drawback is that it is not miscible with mineral oils that is been used in the past and system requirements are strongly dependent on lubricant used. R152a has a better theoretical vapour compression efficient than R12 or R134a and it has a very low GWP. However, compensating factors including operating temperature, heat capacity and thermal conductivity may allow R134a system to be moreefficient comparable to those that can be achieved with R152a. Also because R152a is flammable some researchers have raised concern over its use in an application where non-flammable refrigerant has been the standard. Also while the ozone depletion potential (ODP) of R134a relative to R11 is $\left(<5 \times 10^{-4}\right)$, the global warming potential (GWP) is very high (GWP, 1300), (Kuilpers, 1995; Radermecher and Kim, 2006; Wongwises and Chimres, 2005). The aim of this research therefore, is to look for mixture of eco-friendly refrigerants that can be used to replace this Ozone depletion Freon-12. 


\section{Materials And Method}

Refrigerant mixtures have received renewed interest from designers in the process of searching for new alternatives. By mixing two or more refrigerants, a new working fluid with the desired characteristic can be created by adjusting the composition of a blend containing high pressure refrigerants, the vapour pressure of the final fluid can be tailored to match that of the CFC being replaced (Gopalnarayanan, 1998). Three existing refrigerants namely: R600a (n-butane);R134a (1,1,1,2,tetrafluoroethane) and R406A (55\%R22/4\%R600a/41\%R142b), were considered for this research, taking into consideration their availability, eco-friendliness, safety, non-flammable and low toxicity, (Wongwises and Chimres, 2005). The properties of these selected refrigerants at normal atmospheric conditions are presented in Table 2.

Table 2: The properties of the selected refrigerants

\begin{tabular}{|l|l|l|l|l|l|}
\hline Properties & $\begin{array}{l}\text { Molecular } \\
\text { weight(g) }\end{array}$ & $\begin{array}{l}\text { Boiling } \\
\text { point }\left({ }^{\circ} \mathrm{C}\right)\end{array}$ & Flammability limit in air & $\begin{array}{l}\text { Ozone } \\
\text { potential (ODP) }\end{array}$ & $\begin{array}{l}\text { depletion } \\
\text { warming } \\
\text { potential } \\
\text { (GWP) }\end{array}$ \\
\hline R406A & 89.86 & -32.7 & None & 0.036 & 0 \\
\hline R134a & 102.03 & -26.1 & None & 0 & 1300 \\
\hline R600a & 58.1 & 11.6 & Highly flammable & 0 & 0 \\
\hline
\end{tabular}

Since these selected refrigerants have closely similar thermodynamics properties with R12, hence can be a direct substitute for R12. By mixing two or more of these refrigerants, a new working fluid with the desired characteristics can be created by adjusting of a blend containing high pressure and low pressure refrigerant. The vapour pressure of the final fluid was tailored to match that of the CFC being replaced, as suggested by, Golpalnarayanan, (1998).

In this investigation, several blends of the three refrigerants were tested but ten promising mixturesare as shown in Table 3 follow the suggestions of Hammed and Alsaad (1999), Akintunde (2011); Utulu, 2012, Calm and Didion (1997). To match the properties of single refrigerant with a blend, the individual component was mixed in the right proportions by volume. If refrigerant B is mixed to form a blend, conveying the high pressure first, if a greater amount of $\mathrm{A}$ is added, then the blend will have a pressure closer to $\mathrm{A}$, on the other hand if a greater amount of $\mathrm{B}$ is in the mix, then the blend will have a pressure tend towards B. If equal amount of the refrigerants are mixed the blend will fall between the pressure of A and B, McMullian (2002).

Table 3: Various Rations of the Refrigerant Mixtures

\begin{tabular}{|c|c|c|c|c|}
\hline $\mathbf{S} / \mathbf{N}$ & Code & \% R600a & \%R134a & \% R406A \\
\hline 1. & $\mathrm{R}_{\mathrm{A} 1}$ & 50 & 50 & - \\
\hline 2. & $\mathrm{R}_{\mathrm{B} 1}$ & 50 & - & 50 \\
\hline 3. & $\mathrm{R}_{\mathrm{A} 2}$ & 70 & 30 & - \\
\hline 4. & $\mathrm{R}_{\mathrm{B} 2}$ & 70 & - & 30 \\
\hline 5. & $\mathrm{R}_{\mathrm{A} 3}$ & - & 20 & 80 \\
\hline 6. & $\mathrm{R}_{\mathrm{B} 3}$ & 20 & - & 80 \\
\hline 7. & $\mathrm{R}_{\mathrm{A} 4}$ & - & 60 & 40 \\
\hline 8. & $\mathrm{R}_{\mathrm{B} 4}$ & 40 & 60 & - \\
\hline 9. & $\mathrm{R}_{\mathrm{A} 5}$ & 30 & 70 & - \\
\hline 10. & $\mathrm{R}_{\mathrm{B} 5}$ & 30 & - & 70 \\
\hline
\end{tabular}

During the experiment, consideration was given to the operational pressure and temperature of the control refrigerant (R12) as the base for the experimentations and result comparison. The experiment was carried out first by charging experimental rig with various quantities of R12, and readings were taken at intervals of 30minutes. The prevailing temperatures in the evaporator $\left(T_{e}\right)$ and condenser $\left(T_{c}\right)$ were measured. These were used in conjunction with steam table to determine prevailing enthalpy for the estimation of heat absorbed in the evaporator $\left(\mathrm{Q}_{\mathrm{e}}\right)$ and heat rejected in the condenser $\left(\mathrm{Q}_{\mathrm{c}}\right)$ as indicated in equations (1) and (2). Compressor power was estimated from the thermodynamics properties of R-12 as shown in equation (3). From these results the coefficient of performance was estimated from equation (4) and the efficiency (comparison of COPs of the alternatives with that of R12) from equation (5).

$$
\begin{aligned}
& Q_{\theta}=m_{r}\left(h_{e \varepsilon}-h_{e i}\right) \\
& Q_{c}=m_{r}\left(h_{c e}-h_{c i}\right) \\
& P=m_{y}\left(h_{c p e}-h_{c p i}\right) \\
& \operatorname{COP}=\frac{Q_{q}}{p} \\
& \eta=\frac{\operatorname{COP}_{R}}{\operatorname{COP}_{R 12}}
\end{aligned}
$$

where the subscripts are:

ee - evaporator exit; ei - evaporator inlet 


$\begin{array}{llllll}c e & - & \text { condenser exit; } & c i & - & \text { condenser inlet } \\ \text { cpe } & - & \text { compressor exit } & c p i & - & \text { compressor inlet } \\ r & - & \text { refrigerant } & & & \text { complo }\end{array}$

The second experiment was conducted by first purging the system, and then a mixture of R134a/R600a in the ratio of 50:50 coded RA1 was charged in various quantities into the experimental rig, (a1.492kW/2hp domestic refrigerator). Various values of $T_{e}$ and $T_{c}$ were obtained and compressor power. The system was then purged and other mixtures were introduced, and experiment was carried out in the same way as the previous and reading were recorded.

\section{Result And Discussion}

The overall performance of vapour compression refrigeration system was evaluated by the thermodynamic properties of refrigerant blends and the operational parameters such as energy consumption (input to the compressor) of the system. The quantity of heat absorbed at the evaporator $\left(\mathrm{Q}_{e}\right)$ and the quantity of heat rejected at condenser $\left(\mathrm{Q}_{\mathrm{c}}\right)$ for $\mathrm{R} 12$, and the various mixtures were estimated using equations (1) and (2).The coefficient of performance and compressor power was calculated using equations(3) and (4) respectively, while equation (5) was used to compare the COPs of the blends with that of R12.

Fig. 2 shows the variation of refrigerant flow rate with charging. As show in the figure, the flow rate increases with the refrigerant charge. The increase in the flow rate was gradual until the charging of $850 \mathrm{~g}$ and there was a rapid increase after then. This indicated that, the increase in due to the increase in the pressure as the charging increases. Also the flow pattern for the four blends are the same. RA1 has the highest flow rate while RB1 has the least; both RA2 and RB2 come in between the two. It should be noted that both RA1 and RB1 contained equal percentages of R600a and both of R134a and R407C respectively. The difference in the performance may be traced to higher percentage of R600a in RB1, since R407C contains some percentage of R600a. The results obtained for other blends shown in Table 3 diverged widely from these results; hence they are not included in the result presentation.

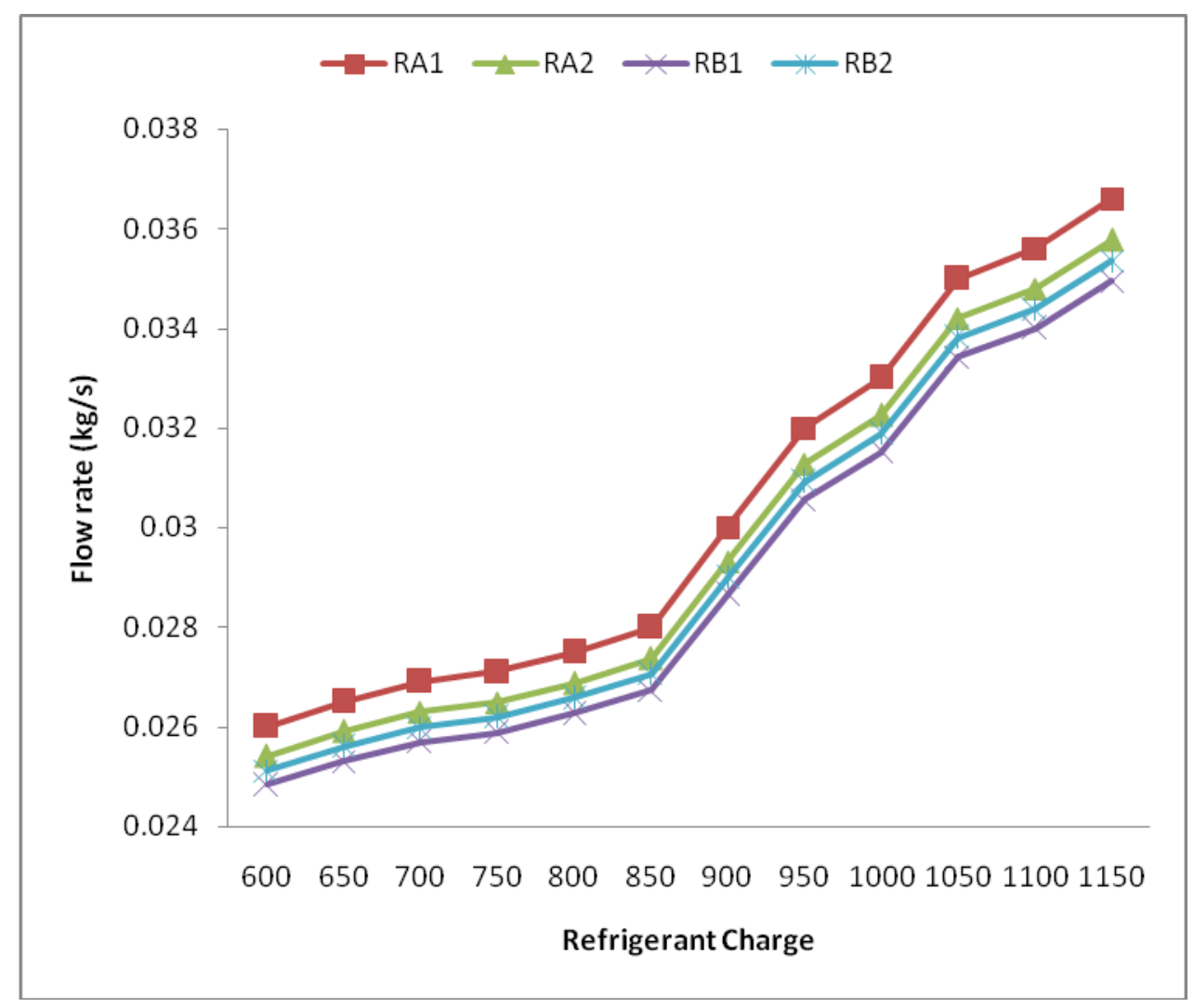

Fig. 2 Variation of Refrigerant Flow Rate with Refrigerant Charge

Fig. 3 is the variation of COP with refrigerant charge. The COPs increase until the charging reaches 850 g. As reported by Akintunde, (2004b) and Lee, et al., (2002), required charging for the capacity of the system used for the experiment should range between $800 \mathrm{~g}$ and $900 \mathrm{~g}$ for maximum effectiveness. The decrease in the COPs after $900 \mathrm{~g}$ of charge is due to flooding of the evaporator and excess pressure in the condenser. Fig, 
4 indicated the variation of refrigeration effects with the refrigerant charge. From both figures (3) and (4) the results indicated that he four refrigerant blends can be used as replacement for R12.

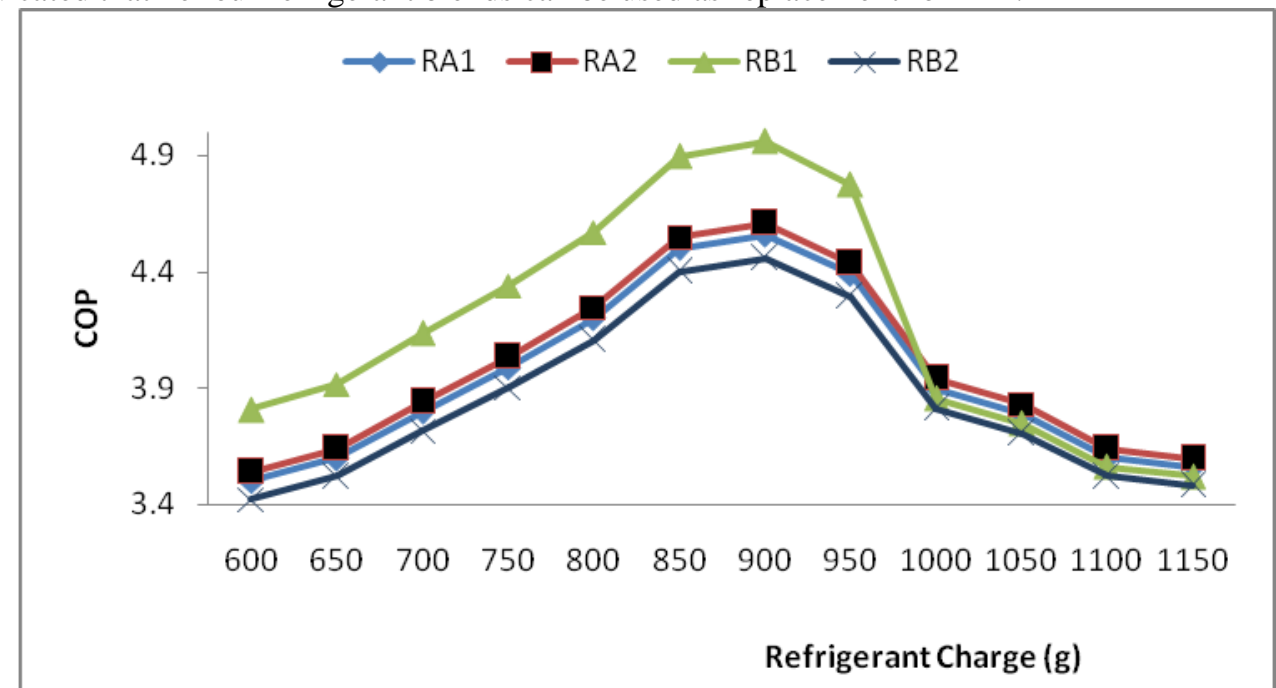

Fig.3 Variation of COP with refrigerant Charge

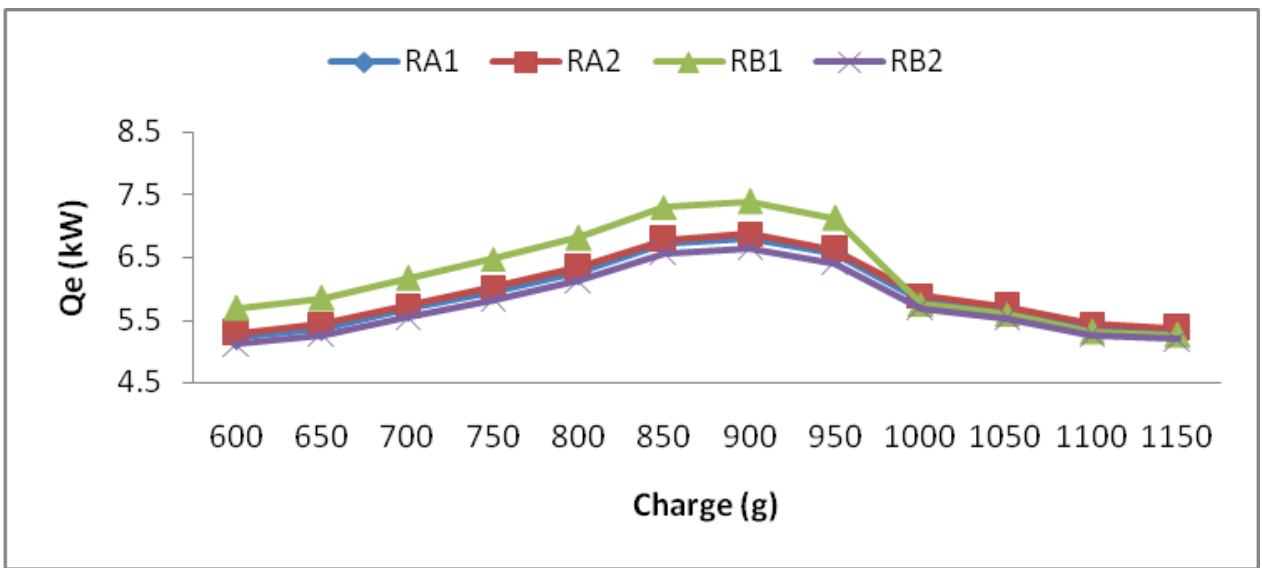

Fig. 4 Variation of $\mathrm{Q}_{\mathrm{e}}$ with Refrigerant Charge

The efficiency of the refrigerant blends was defined as the relative COPs with respect to that of R12, (equation (5)). The result is as shown in Fig. 5. The figure shows that irrespective of quantity of charging the efficiency or relative COPs remain constant. The relative COPs for RA1, RA2 and RB2 remain as 96\%, 99\% and $98 \%$ respectively. The relative COP for RB1 is higher than that of R12 until the quantity of charging reaches $950 \mathrm{~g}$, and it dropped sharply after then. In between $600 \mathrm{~g}$ and $950 \mathrm{~g}$, the relative COP stands at $106 \%$ and it falls to $97 \%$ when the quantity of the charge was increased to $1000 \mathrm{~g}$ and above.

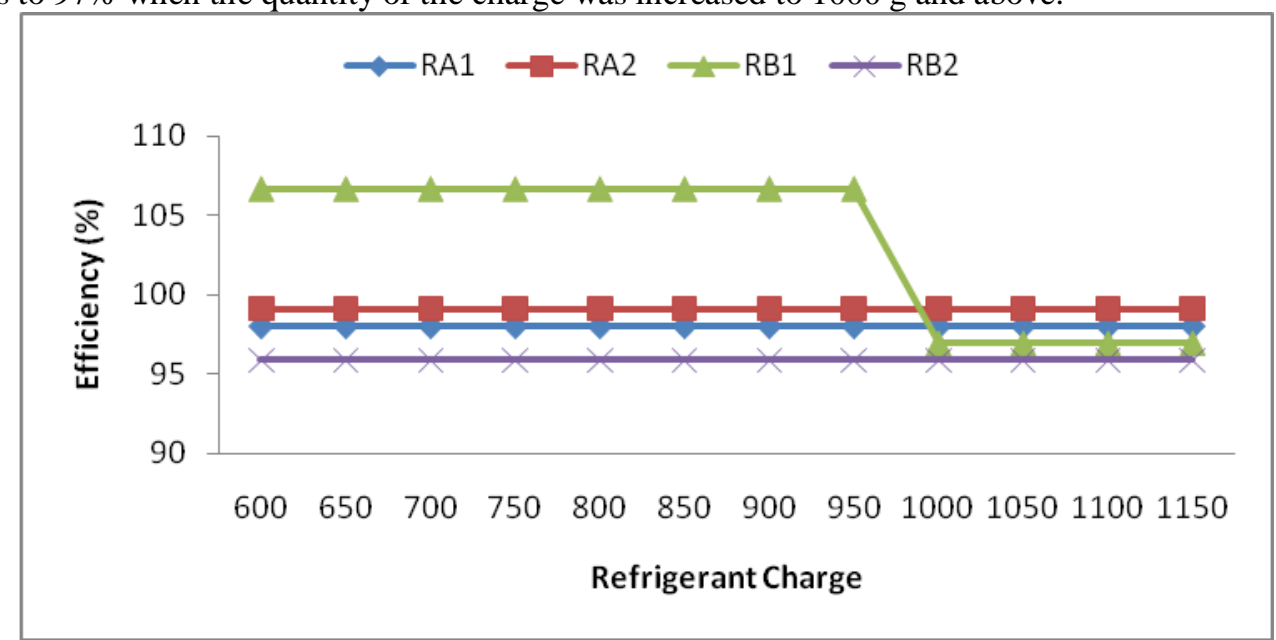

Fig.5 Efficiency of the Refrigerant blends relative to R12 
As shown in figures (2) to (5) RA1, RA2, RB1 and RB2 can be used as alternative to R12 provided the charging quantity ranges between $600 \mathrm{~g}$ and $900 \mathrm{~g}$. Further works were done on the transport properties of the refrigerant blends by Akintunde, (2013). From the results gotten by Akintunde (2013) and this present study, the blends considered and reported on can be used as alternative to R12.

\section{Conclusion}

This research focuses on refrigerant blends as alternatives to R12, one of the principal actors in ozone depletion. In accordance with the set objectives, the experimented refrigerant mixtureswere obtained by blending varying proportion of R600a, R134a and R406A.The refrigerant blends were experimented in an existing refrigerator unit, which was designed to use R12 as its working fluid.RA2 which is the blend of $70 \% \mathrm{R} 134 \mathrm{a} / 30 \% \mathrm{R} 406 \mathrm{~A}$ was observed to have similar operating conditions asthat ofR12. The performance observed, during experimentation, justified that compressors designed for R12 can be used for RA2, without changing compressor lubricating oil. The obtained results of the refrigerant blends were then compared with that R12. The overall assessment of the result favoured the use of RA1, RA2, RB1 and RB2 refrigerantsblends as alternative to R12., but the performance was obtained from the use RA1 mixture in the system. The results show that irrespective of quantity of charging the efficiency or relative COPs remain constant. The relative COPs for RA1, RA2 and RB2 remain as 96\%, 99\% and 98\% respectively. The relative COP for RB1 is higher than that of R12 until the quantity of charging reaches $950 \mathrm{~g}$, and it dropped sharply after then. In between $600 \mathrm{~g}$ and $950 \mathrm{~g}$, the relative COP stands at $106 \%$ and it falls to $97 \%$ when the quantity of the charge was increased to $1000 \mathrm{~g}$ and above.

\section{Reference}

[1]. Akintude, M.A; Adegoke C.O; Fapetu, O.P (2004), "Experimental Investigation of the Performance of A Design Model for Vapour Compression Refrigeration System". West Indies Journal of Engineering. Vol. 28 No: 2, pp 80-87

[2]. Akintunde, M. A. (2004), Experimental Investigation of the Performance of R12 and R134a in Capillary Tubes for Refrigeration Systems. Journal of Engineering Science and Technology, University of Ilorin. Vol. 4 No:1, pp 1 - 12.

Akintunde, M. A. (2004b) "Theoretical Design Model for Vapour Compression Refrigeration Systems". -AMSE Periodicals, France. Vol. 73 No: 5, pp $1-14$.

[4]. Akintude, M.A. (2006). Experimental Investigation and Modeling solubility in R12 and R13a. Journal of Engineering and Applied science, Vol 1 No 1 pp 14-22

[5]. Akintude, M.A. (2006). Validation of a Vapour Compression Refrigeration System Design Model. American Journal of scientific and Industrial Research (AJSIR). Vol 2 No 4, pp 504-510.

[6]. Akintude, M.A. (2013)Experimental Investigation of Thermal Conductivity and Thermal Diffusivity of New Refrigerants Blends.International Journal of Emerging Trends in Engineering and Applied Sciences (JETEAS). Vol. 4 No: 2 , pp 328 - 332.

[7]. Bhatti, M.S. (1999). A historical Look at chlorofluorocarbon Refrigerant ASHRAE transaction, part 1.Pp 1186-12006.

[8]. Calm, J. M. (2002). Emission and environmental impacts from air-conditioning and refrigeration.International Journal of Refrigeration. Vol. 25, No: 7, pp 293 - 305.

[9]. Calm, J.M and Didion, D.A. (1997). Trade- offs in refrigerants selections: Past, present and future. American Socierty of Heating refrigerating and Air-conditioning Engineers (ASHRAE), Inc. Altanta (GA):pp 433-444

[10]. Chivian, A.E; McCally, M; Hu and Haines, A. (1993).Loss of stratospheric Ozone and health effect of increase ultra violent radiation. The MIT press Cambridge.

[11]. Domanski, P.A and Mclinden, M.O (1992). A simplified Cycle Simulation model for the performance rating of Refrigerants and Refrigerants Mixtures. International Journal of Refrigeration.Vol 115, No: 2 pp 81-88

[12]. Eckels, S.J and Tesene, B.A (2003). A Comparison of R22, R134a, R410A and R407C, Condensation Performance in Smooth and Enhance Tubes: Part 1, Heat Transfer ASHIRAE Transaction, pp 428-441.

[13]. Gopalnarayanan S. (1998). Choosing the right refrigerant.Mechanical Engineering, published by the American society of Mechani cal Engineer (ASME).Vol 11120 No 11.Pp 1181- 1189

[14]. Hwang, Y. Ohadi; M and Radermacher, R (1998).Natural Refrigerants. Mechanical Engineering published by American society of Mechanical Engineers (ASME). Vol 1120 No 10, pp 96-99

[15]. Kuijper, L. (1995). Hydrocarbon and the Montrel Protocol Mechanism. Proceedings of International CFC and Halon attentive conference, Washington D.C., October 23-25: pp 167-173.

[16]. Lee, J. H.; Bae, S. W. Bang, K. H.; and Kim, M. H. (2002).Experimental and numerical research on condenser performance for R-22 and R- 407C refrigerants.International Journal of Refrigeration. Vol. 25, No: 8, pp $372-382$.

[17]. McMullian, T.J (2002). Refrigerator and the environment issues and strategies for the future international Journal of refrigeration Vol. 25 No 5; pp 89-99

[18]. Radermacher, R and Kim, K (2006).Domestic refrigeration Recent Development. International Journal of Refrigeration, Vol 119 pp $58-62$

[19]. Stoecker, W.F. (1983). Improving the Energy Effectiveness of demerits refrigerator by the application of refrigerant mixtures cont830568-1, in; proceeding of the international technical application conference Indiana, pp 3-9

[20]. Wongwises, S. and Chimres, N, (2005). Experimental study of hydrocarbon mixtures to replus HCF134a in a Domestic refrigerator, Energy Conservation and Management, Vol. 46 pp 85-100 